\title{
CATALYTIC CONVERSION OF GLYCEROL AND SUGAR ALCOHOLS TO VALUE-ADDED PRODUCTS
}

\author{
Mohanprasad A. Dasari \\ Dr. Galen J. Suppes, Dissertation Supervisor
}

\begin{abstract}
\end{abstract}
The current research is based on developing an improved and fundamental understanding of technology that will allow the conversion of this crude glycerin to a propylene glycol based antifreeze product.

Hydrogenolysis of glycerol to propylene glycol was performed using copper chromite catalyst. At temperatures above $200^{\circ} \mathrm{C}$ and hydrogen pressure of 200 psi, the selectivity to propylene glycol decreased due to excessive hydrogenolysis of the propylene glycol. The yield of propylene glycol increased with decreasing water content. The main causes for the deactivation were reduction of the cuprous chromium active species into metallic copper species, metal leaching, and blocking of sites by strongly adsorbed inorganic and organic species present in the feed or generated during the reaction.

A new reaction pathway for converting glycerol to propylene glycol via an intermediate was validated by isolating the acetol intermediate. In the first step involves dehydration of glycerol to acetol with subsequent hydrogenation of acetol to propylene glycol. High acetol selectivities (>90\%) were achieved using copper-chromite catalyst and operating in semi-batch reactive distillation mode. The acetol from this reaction readily hydrogenates to from propylene glycol with selectivities exceeding 95\%. 